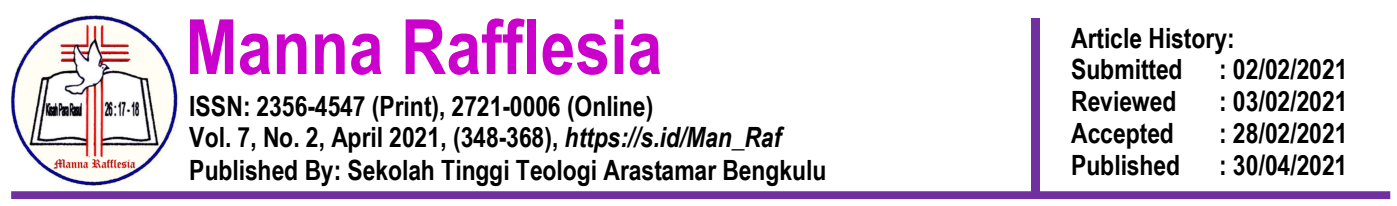

\title{
TEOLOGI PENGGEMBALAAN YEHEZKIEL DALAM MENGHADAPI TANTANGAN KEHIDUPAN JEMAAT
}

\author{
Linda Zenita Simanjuntak ${ }^{1}$ ), Samuel Abdi $\mathrm{Hu}^{2}$, Lugimin Aziz $^{3}$ \\ Sekolah Tinggi Teologi Arastamar Riau ${ }^{1}$, \\ Sekolah Tinggi Teologi Sumatera Utara ${ }^{23}$ \\ *) Email Correspondence: lindasimanjuntak190278@gmail.com
}

This paper departs from ideas on facts in various parts of the world, especially the
shepherding segment of Christian theology. As a prophecy, of course, the prophet
Ezekiel had many essential messages for the life of the Shepherds at that time.
Ezekiel 34 as one of the crucial parts of prophecy for today's readers, especially the
field of practical theology deserves to be studied to obtain meaningful guidance for
Pastors of the Congregation in shepherding a group of people who are facing
various challenges in life. These various challenges were even more complicated
when the corona pandemic was declared in 2020. By using the literature review
method, the researcher explores various works of literature to answer the needs in
the field, especially pastoral theology as part of practical theology. The results of
the research state that the spirit of shepherding must not be diminished by the
increasingly complex challenges of life. This prophetic content in Ezekiel 34
addresses two different areas, namely the judgment of hope in Christ. As a
prophecy, Ezekiel 34 gives the sheep the joyous hope of waiting for God's
intervention during misleading shepherding practices. On the other hand, some
Shepherds actually have the opportunity to show the strength and leadership. God
has given wise tools and wisdom to the Pastors to lead the congregation to the
comfort and comfort of life both physically and spiritually.
Pastor, practical theology, pastoral care, challenges of life, Ezekiel

Abstrak: Artikel ini berangkat dari gagasan tentang fakta di berbagai belahan dunia, khususnya segmen penggembalaan dalam teologi Kristen. Sebagai sebuah nubuatan, tentunya nabi Yehezkiel memiliki banyak pesan penting bagi kehidupan para Gembala saat itu. Yehezkiel 34 sebagai salah satu bagian nubuat yang krusial bagi para pembaca saat ini, khususnya bidang teologi praktis patut untuk dikaji guna memperoleh tuntunan yang bermakna bagi para Gembala Jemaat dalam menggembalakan sekelompok orang yang menghadapi berbagai tantangan dalam hidup. Berbagai tantangan tersebut semakin pelik ketika pandemi corona dideklarasikan pada awal tahun 2020. Dengan menggunakan metode studi pustaka, peneliti menggali berbagai karya sastra untuk menjawab kebutuhan di lapangan, khususnya teologi pastoral sebagai bagian dari teologi praktis. Hasil penelitian menyatakan bahwa semangat penggembalaan tidak boleh diredupkan oleh tantangan hidup yang semakin kompleks. Isi nubuatan dalam Yehezkiel 34 ini membahas dua bidang yang berbeda, tentang penghakiman dan pengharapan di dalam Kristus. Dalam hal pengharapan nubuatan, Yehezkiel 34 memberi dombadomba itu harapan penuh sukacita untuk menunggu campur tangan Tuhan selama praktik penggembalaan yang menyesatkan. Di sisi lain, sebagian Gembala justru memiliki kesempatan untuk menunjukkan kekuatan dan kepemimpinan. Tuhan telah memberikan alat dan kebijaksanaan bijak kepada para Pendeta untuk memimpin jemaat pada kenyamanan hidup baik secara fisik maupun spiritual.

Kata Kunci: Gembala, Teologi Praktika, Penggembalaan, Tantangan Kehidupan, Yehezkiel 


\section{PENDAHULUAN}

Penggembalaan mendapat tantangan baru setelah penetapan pandemik corona viruses desease 2019 (covid-19) pada bulan Maret 2020 lalu. Di antaranya adalah pelayanan tatap muka (on-site) beralih ke online melalui beragam media sosial, diantaranya youtube, facebook (FB), Instagram (IG), zoom meeting dan lain sebaginya. Keadaan tersebut menyebabkan banyak pendeta mengurangi kontak langsung secara tatap muka kepada jemaat. Darwin Tobing Ephorus Huria Kristen Batak Protestan (HKBP) (2012 - 2020) sebelumnya mempertanyakan kesiapan pendeta dalam menghadapi arus perubahan dalam banyak aspek di kehidupan Gereja dan warganya. ${ }^{1}$ Pernyataan tersebut menunjukkan ada masa akan adanya perubahan kehidupan dalam bidang ekonomi, sosial masyarakat yang dikenal saat ini dengan new normal (normal baru), perubahan tersebut berdampak bagi bidang penggembalaan.

Penelitian Simon dan Anderson menunjukkan berkurangnya rasa kemanusiaan, rasa empati terhadap orang lain namun bersamaan dengan itu tumbuh sikap paranoid. ${ }^{2}$ Penelitian lainnya yang menyoroti berbagai aspek dampak pandemik tersebut dilakukan oleh Teng dan Margaret yang menunjukkan adanya ambiguitas pelayanan sebelum pandemik covid-19 telah tampak dalam jemaat, $^{3}$ salah satunya sikap malas jemaat untuk datang beribadah ke gereja. Hutahaean mengamati fenomena perubahan pelayanan dari pola tatap muka kepada media sosial secara online tidak terhindarkan. Dalam penelitiannya,

1 Darwin Lumbantobing, "Pendeta Dalam Fungsi Koinonia, Marturia dan Diakonnia," dalam Merangkai Teologi Kehidupan Terkini, ed. oleh Wilda Simanjuntak (Siantar: L-SAPA, 2008), 1-18.

2 simon Simon Dan Lindin Anderson, "Covid-19 Memudarkan Rasa Kemanusiaan Terhadap Sesama Dan Implikasinya Bagi Orang Percaya," Sabda: Jurnal Teologi Kristen 1, no. 2 (2020): 85-104, https://doi.org/ISSN: 2722-306X.

3 Michael Teng dan Margaret Carmia, "Sketsa Pelayanan Gereja Sebelum, Selama, Dan Sesudah Masa Pandemi Covid-19," Veritas: Jurnal Teologi dan Pelayanan 19, no. 2 (2020): 201-13, https://doi.org/10.36421/veritas.v19i2.432. 
terdapat $24 \%$ responden (dari 100 responden) yang menginginkan agar pelayanan secara online diteruskan meski penetapan pandemik telah dihapus dimasa akan datang. ${ }^{4}$ Melihat fakta itu berarti pergeseran pelayanan penggembalaan tidak bisa dihindarkan setelah pandemik covid-19. Penelitian Asmad Purba menekankan peran orang tua untuk mendidik dan membentuk karakter anak pada saat anggota keluarga lebih banyak menghabiskan waktu di rumah. ${ }^{5}$ Jansakti dari Gereja Kristen Setia Indonesia (GKSI) Merauke memberikan pendapat berbeda bahwa khotbah di hari minggu mempunyai pengaruh terhadap pertumbuhan iman jemaat ${ }^{6}$ Kedua penelitian tersebut menunjukkan perbedaan sikap dalam membina jemaat, selanjutnya Jansakti juga menuliskan bahwa pola berkhotbah perannya sangat kecil dalam menumbuhkembangkan iman jemaat. ${ }^{7}$ Fakta-fakta dari penelitian tersebut menunjukkan bahwa jemaat semakin kritis dan teliti dalam menilai pelayanan penggembalaan.

Penelitian di atas telah menunjukkan adanya kebutuhan pegangan dalam pemahaman teologi penggembalaan di masa kini. Satu sisi kehidupan semakin menemukan tantangan yang beragam, namun di lain pihak penggembalaan tidak bisa dilakukan dengan pola-pola lama sehingga dibutuhkan inovasi baru. Hal yang menonjol dalam era pandemik covid-19, penggembalaan tidak lagi menggunakan tatap muka namun sistem online. Gembala mengekspresikan rasa belas kasihan atas dukacita yang dialami jemaat melalui media online dan kurangnya

4 Hasahatan Hutahaean, Bonnarty Steven Silalahi, dan Linda Zenita Simanjuntak, "Spiritualitas Pandemik: Tinjauan Fenomenologi Ibadah Di Rumah," Evangelikal: Jurnal Teologi Injili dan Pembinaan Warga Jemaat 4, no. 2 (1 Agustus 2020): 234-49, https://doi.org/10.46445/ejti.v4i2.270.

${ }^{5}$ Asmat Purba, "Tanggung Jawab Orang tua Kristen dalam Mendidikan Anak Menyikapi Pandemi Covid-19," Epigraphe: Jurnal Teologi dan Pelayanan Kristiani 4, no. 1 (2020): 86-97, https://doi.org/10.33991/epigraphe.v4i1.148.

6 Jansakti Saddu Saly dan Hasahatan Hutahaean, "Pengaruh Khotbah Dalam Ibadah Minggu Terhadap Kedewasaan Iman Jemaat Di Gksi Merauke," Visio Dei: Jurnal Teologi Kristen 2, no. 2 (2020): 225-43, https://doi.org/10.35909/visiodei.v2i2.165.

7 Saly dan Hutahaean. 
percakapan yang panjang antara gembala dan jemaat. Situasi menuntut bidang penggembalaan berkreasi, agar kasih Allah tetap dirasakan jemaat.

Tugas penggembalaan dalam gereja memiliki banyak kesamaan dengan tugas para pendidik baik dosen atau guru. ${ }^{8}$ Telaumbanua menyatakan bahwa dalam penggembalaan terdapat aktivitas mengajar seperti yang dilakukan pendidik, tidak hanya materi pelajaran tetapi nilai-nilai kehidupan agar orang yang diajar atau digembalakan menuju taraf kehidupan yang lebih baik. Dua puluh tahun lebih sebelum pendapat tersebut, Fowler juga menyatakan bahwa proses pendidikan Kristen pada dasarnya bertujuan agar orang-orang dibentuk dalam pimpinan Roh Kudus, agar Allah dapat menyatakan diri-Nya di dunia ini melalui orang-orang tersebut. ${ }^{9}$ Dari tulisan Waharman, dapat dipahami besarnya ekspektasi gembala yang benar terhadap kenyamanan domba-dombanya. Berbagai aktifitas gembala yang digambarkan dalam Mazmur 23 yakni menjaga, memelihara, mencari yang tersesat dengan tujuannya supaya domba-domba-nya tetap dalam perlindungannya. ${ }^{10}$ Selanjutnya Yehezkiel menuliskan pengalaman spiritualnya dari Allah ketika menerima nubuatan tentang gembala-gembala di Israel (Yeh.34:2). Yehezkiel 34 dibagi menjadi tiga dalam isinya, pertama, yang tidak diinginkan Allah dari seorang gembala umat-Nya, kedua, yang akan

\footnotetext{
${ }^{8}$ Arozatulo Telaumbanua, "Peran Gembala Sidang Sebagai Pendidik Dalam Pertumbuhan Rohani Jemaat," Fidei: Jurnal Teologi Sistematika dan Praktika 2, no. 2 (2019): 362-87, https://doi.org/10.34081/fidei.v2i2.45.

9 JW Fowler, "Teologi Praktika dan Pembentukan Hidup Orang Kristen," dalam TEologi dan Praksis Pastoral Antologi Teologi Pastoral, ed. oleh Tjaard G Hommes dan E Gerrit Singgih (Yogyakarta: Kanisius, 1992), 355-78.

10 Waharman Waharman, "Prinsip Penggembalaan Dalam Mazmur 23," Manna Rafflesia 1, no. 2 (2015): 93-111, https://doi.org/10.38091/man_raf.v1i2.47.
} 
dilakukan Allah kepada gembala dan ketiga apa yang akan dilakukan Allah terhadap domba-domba tersebut. ${ }^{11}$

Teologi praktika menjadi salah satu usaha teologis yang logis meliputi konstruksi eksegetikal, historikal, sistematik dan fundamental ${ }^{12}$ untuk menjadi $^{2}$ pegangan bagi orang-orang yang bergelut di bidangnya. Dengan berpedoman pada Yehezkiel 34 sebagai tulisan dengan genre nubuat, menurut peneliti penting untuk menghubungkannya dengan situasi penggembalaan pasa masa kini yang semakin kompleks, untuk dapat dijadikan bagian dalam tuntunan kepada gembala untuk membawa jemaat kepada kehidupan spiritualitas yang lebih baik di hadapan Allah. Sehingga ditemukan satu kajian yang berguna bagi gembala dan sivitas akademika pada khususnya namun tak kalah penting bagi kehidupan jemaat pada umumnya. Tulisan ini akan mengungkap jawaban atas situasi terkini bagi bidang penggembalaan yang semakin banyak tantangan.

\section{METODE}

Peneliti menggunakan penelitian kepustakaan yang digolongkan pada metode kualitatif, khususnya dengan pendekatan interpretative. ${ }^{13}$ Atau juga dikenal sebagai sebuah pendekatan yang memaknai perilaku secara detail dalam observasi langsung dengan memahami makna yang terdapat dalam tiap fakta yang ada secara objektif dan netral. Hal ini juga seturut dengan tujuan teologi praktika dari Castella, agar interpretasi Kitab Suci yang berguna pada masa kepenulisannya, dapat dimanfaatkan untuk membebaskan, menghibur dan sumber

11 Simon Petrus Siahaan, "Konsep Gembala Menurut Yehezkiel 34:1-16 Serta Implikasinya Bagi Gembala Jemaat," Missio Ecclesiae 4, no. 2 (2015): 123-54, https://doi.org/ISSN: 2721-8198.

12 Fowler, "Teologi Praktika dan Pembentukan Hidup Orang Kristen."

${ }^{13}$ Amir Hamzah, Metode Penelitian Kepustakaan, Revisi (Malang: Literasi Nusantara, 2020). 
inspirasi untuk tindakan serta perilaku bagi pembaca masa kini. ${ }^{14}$ Langkahlangkah dalam penelitian ini adalah dengan menyajikan fakta sosial yang dibandingkan dari teks Alkitab yang kemudian diidentifikasi masalahnya. Setelah itu peneliti akan menguraikan usulan untuk dijadikan solusi dalam mengatasi masalah sosial yang ada. Karena pertama-tama akan dipaparkan isi nubuatan dari sisi penghakiman serta harapan atau keselamatan. Dari sana peneliti akan memaparkan dengan jelas maksud Allah dalam nubuat tersebut, bagi kehidupan penggembalaan pada masa kini. Sehingga deskripsi itu nantinya menjadi insight yang berarti bagi dunia teologi praktika khususnya teologi penggembalaan.

\section{HASIL}

Kitab Yehezkiel 34 disampaikan dengan gaya nubuat terhadap gembalagembala yang hanya menggembalakan diri sendiri. Domba-domba menjadi sumber benefit (cash and non-cash), sedangkan spiritualitas mereka tidak bertumbuh dan dibiarkan tanpa penggembalaan yang sungguh-sungguh. Yehezkiel menerima nubuatan dari Allah sebagi pemilik para domba. Pasal 34 berisi nubuatan yang mengandung dua unsur sebagaimana genre nubuat, yakni penghakiman dan harapan. ${ }^{15}$ Sebagai sebuah genre nubuat, menurut John Drane isi nubuat berupa pertama penghukuman atau penghakiman Allah atau kedua berupa janji serta karya keselamatan bagi umat-Nya. ${ }^{16}$ Selanjutnya Joel B Green

\footnotetext{
14 Casthelia Kartika, "Meninjau Ulang Metode Teologi Praktika Dalam Karya IImiah Di Bidang Pendidikan Teologi," Jurnal Amanat Agung 9, no. 1 (2013): 101-18, https://doi.org/10.47754/jaa.v9i1.124.

15 Joel B. Green, Memahami Nubuatan, ed. oleh James Pantou (Jakarta: Persekutuan Pembaca Alkitab, 2005), 65.

${ }^{16}$ John Drane, Memahami Perjanjian Lama II: dari Kerrajaan Terpecah Sampai Pascapembuangan (Jakarta: Scripture Union Indonesia, 2017).
} 
menekankan nubuat yang berisi penghukuman dan harapan. ${ }^{17}$ Pattinama menuliskan bahwa bangsa yang hilang adalah bangsa Israel. ${ }^{18}$ Tiga penghukuman Allah kepada Gembala-gembala yakni; pertama, Aku sendiri akan menjadi lawan gembala-gembala itu (ay.10.b). Kedua, Aku akan menuntut kembali domba-domba-Ku dari mereka (ay.10.c), dan ketiga, Akan memberhentikan mereka menggembalakan domba-domba-Ku (ay.10.d). Tiga perbuatan Allah terhadap gembala ini menujukkan perhatian dan kecintaanNya yang sangat besar kepada manusia yang dipilihNya, yang digembalakan. Dengan demikian Allah menunjukkan bahwa Dia tidak akan tinggal diam terhadap gembala-gembala palsu, demikian juga tidak tinggal diam melihat para domba menuju kebinasaan dan ketersesatan.

Yehezkiel 34 memberikan gambaran tentang para gembala sebagai berikut:

Yang dilakukan Allah kepada domba-domba-Nya

1. Melepaskan domba-domba-Ku dari mulut mereka, sehingga tidak terus lagi menjadi makanannya melepaskan domba-domba-Ku dari mulut mereka, sehingga tidak terus lagi menjadi makanannya (ay.10.e)

2. Aku sendiri akan memperhatikan domba-domba-Ku dan akan mencarinya (ay.11)

3. Aku akan mencari domba-domba-Ku yang tercerai-berai (ay.12a)

4. Aku akan menyelamatkan mereka dari segala tempat (ay.12b)

5. membawa mereka keluar dari tengah bangsa-bangsa. Mengumpulkan dari negeri-negeri agar kembali ke tanah mereka (ay.13a) di rumput yang baik, di pegunungan Israel (ay.14)

6. Aku akan menggembalakan mereka (ay.13b; ay.15)

17 Green, Memahami Nubuatan.

18 Yenny Anita Pattinama, "Pastoral Konseling Menurut Yehezkiel 34:16 Sebagai Upaya Pemulihan Mental," Scripta: Jurnal Teologi dan Pelayanan Kontekstual 6, no. 2 (2018): 176, https://doi.org/10.47154/scripta.v6i2.53. 
7. Akan menggembalakan mereka sebagaimana seharusnya (ay.16), yakni yang hilang akan Kucari, yang tersesat akan Kubawa pulang, yang luka akan Kubalut, yang sakit akan Kukuatkan, serta yang gemuk dan yang kuat akan Kulindungi

8. Aku akan menjadi hakim di antara domba dengan domba (ay.17; ay.22), kambing dengan domba, domba yang gemuk dengan domba yang kurus (ay.20)

9. Mengangkat Daud jadi gembala dan Raja atas domba-domba (ay.23-24)

10. Akan meniadakan binatang buas diantara mereka (ay.25a)

11. Aku akan mengadakan perjanjian damai, supaya mereka tentram, dan dapat tidur (ay.25)

12. akan menurunkan hujan yang menjadi berkat pada waktunya (ay.26)

13. Mereka akan mengetahui, bahwa Akulah TUHAN (ay.27)

14. mendirikan bagi mereka suatu taman kebahagiaan (ay.29)

Tabel. 1 Tindakan Allah kepada domba-Nya

\section{PEMBAHASAN}

Sumiwi menuliskan bahwa gembala mempunyai gerak yang boleh melewati aturan demi keperluan jemaat. ${ }^{19}$ Meski demikian, “jalur" khusus ini tidak dipergunakan semena-mena untuk keperluan individu gembala. Tetapi semata-mata demi keperluan pertumbuhan iman jemaat dalam menjalani kehidupan yang kian hari kian berat tantangannya. Terhadap tantangan demi tantangan dalam kehidupan jemaat perlu performa mumpuni dan kesucian hidup dengan didorong atas panggilan pelayanan yang diterimanya dari Allah, Sang Pemilik pelayanan. Karena itu, pada masa pandemik gembala dituntun kian menunjukkan kepeduliannya terhadap situasi jemaat dalam kesehatan, ekonomi, kekuatiran dan ketakutan lain yang berkaitan dampak masa tersebut. Selanjutnya

19 Asih Rachmani Endang Sumiwi, "Gembala Sidang yang Baik Menurut Yohanes 10 : 1-18," Harvester: Jurnal Teologi dan Kepemimpinan Kristen 4, no. 2 (2019): 74-93, https://doi.org/e-ISSN 26850834. 
Johannis menuliskan salah satu kasus pada masa kini, ada banyak yang hilang karena penyalagunaan narkoba. $^{20}$ Dengan demikian kehidupan orang Kristen masa kini telah banyak yang sesat ibarat dimangsa binatang buas, serta menuju jalan yang lain, dan tidak sedikit yang sakit namun dibiarkan oleh para gembala.

Melihat tindakan Allah seperti dalam tabel di atas, tampak perhatian dan aksi Allah berpihak kepada umatNya agar menikmati ketenangan dan kenyamanan sama seperti yang dituliskan dalam Mazmur 23. Pokok ini perlu menjadi perhatian para gembala jemaat agar melihat ketenangan dan kenyamanan jemaat bukan sebagai pilihan dalam pekerjaan pelayanannya. Ketenangan dan kenyamanan ini mencakup jasmani dan rohani, sehingga ada tingkat spiritualitas yang tinggi dalam diri jemaat. Para gembala untuk mencapai ekspektasi ini membutuhkan tenaga, pikiran dan waktu lebih dari hanya memenuhi tugas dan jadwal pelayanan. ${ }^{21}$ Dalam suasana pandemik covid-19 perlu perlakuan dan inovasi khusus dari para gembala dalam menuntun jemaat untuk menikmati ketenangan dan kenyamanan jasmani dan rohani. Yesus Kristus telah memberikan berbagai prinsip pelayanan di tengah krisis dengan aktif membuka dialog yang memiliki dasar teologi dan komunikasi yang benar. ${ }^{22}$

Yehezkiel memakai gambaran domba dan gembala untuk menunjukkan orang-orang pilihan Allah yang terlantar dari penggembalaan pelayanan pastoral. Para gembala adalah para pemimpin Gereja, yang mendapat tugas dalam pelayanan pastoral, namun tidak menjalankan tugas pokok dan fungsinya. Riemer

\footnotetext{
${ }^{20}$ Abraham Johannis, "Peran Gembala Dalam Upaya Pencegahan Penyalahgunaan Narkoba Pada Anak Remaja," dalam Moderasi Teologi Kristen (Jakarta: Covindo, 2020), 250. 2020).

21 Hasahatan Hutahaean, Pelayan Tuhan di Gereja dan Masyarakat (Luwuk: Pustaka Star's Lub,

22 Berton Bostang Hamonangan Silaban, "Strategi Konseling Yesus Menurut Lukas 24:13-25 Dan Kontribusinya Terhadap Konseling Krisis Masa Kini," Asteros 3, no. 2 (2016): 39-50, https://doi.org/ISSN. 2356-2587.
} 
menuliskan agar penatua mengenal masing-masing nama dan keadaan jemaat secara pribadi, baik dalam susah dan sukacita. $^{23}$ Dengan demikian penulis menekankan agar penggembalaan berani memasuki ranah pelayanan yang mengikuti perubahan dan tantangan dalam kehidupan jemaat, baik dalam kesehatan, kemiskinan dan tekanan sosial agar melalui pelayanan itu kehadiran kerajaan Allah dapat dirasakan jemaat.

Pada ayat 23-24 ada kalimat yaitu "mengangkat Daud jadi gembala dan Raja atas domba-domba." Balchim menuliskan nubuatan pasal 1-24 ditulis sebelum 587 SM, bahkan nubuatan-nubuatan pasal 33-39 untuk Yerusalem setelah kejatuhannya. ${ }^{24}$ Jika mengikuti kisah Daud membangun Yerusalem dan sebelumnya, ${ }^{25}$ maka kelahiran Daud diperkirakan 1040 SM. Karena itu dapat dipastikan bahwa nubuatan ini diterima jauh setelah Daud meninggal dan dengan demikian kata "mengangkat Daud" tidak dapat dipahami secara harafiah. Menurut peneliti, kata "mengangkat Daud” merupakan konotasi merujuk kepada kekuatan pemerintahan Daud yang sanggup melepaskan Israel dari kekuatan Filistin dan sekutunya. Peneliti melihat bahwa Mazmur 23 (dari Daud) telah dikenal oleh Yehezkiel, sehingga Allah memberikan nubuat itu dengan menggunakan kata "mengangkat Daud" sebagai bentuk pemahaman Allah sebagai Gembala yang memberikan ketenangan dan menyediakan rumput hijau, seperti dinyanyikan Daud dalam Mazmur 23 itu. Stovell juga menjelaskan bahwa penggunaan kata "mengangkat Daud" sebagai gambaran kekuatan Allah melalui keturunan Daud

23 G Riemer, Jemaat Yang Pastoral; Kunjungan Rumah Pacu Jantung Pertumbuhan Gereja (Jakarta: Yayasan Komunikasi Bina Kasih, 2005).

${ }^{24}$ John Balchin dkk., Intisari Alkitab Perjanjian Lama (Jakarta: Scripture Union Indonesia, 2016).

25 John Drane, Memahami Perjanjian Lama; Dari Bapa Leluhur sampai Kerajaan Bersatu (Jakarta: Scripture Union Indonesia, 2017). 
yang kelak akan menggembalakan umatNya. ${ }^{26}$ Karena itu terjemahan Bahasa Indonesia Sehari-hari (BIS), lebih tepat, dan dapat memberi jembatan pemahaman bagi pembaca masa kini karena istilah "mengangkat Daud" diterjemahkan dengan "...mengangkat seorang raja yang seperti hamba-Ku Daud..." kata itu bukan merujuk pada Daud secara harafiah, namun bentuk nubuat terhadap Mesias yang akan datang memberikan keselamatan pada Israel.

Yehezkiel menerima nubuatan tentang orang Israel di Yerusalem dan para gembala disana. Rajo menuliskan bahwa Yehezkiel diutus untuk memberitahu dan memperingatkan orang Israel agar tidak berbuat dosa dan bertransformasi dengan hidup yang gemilang. ${ }^{27}$ Dengan demikian Yehezkiel selain menegur para gembala, juga menegur umat Israel. Jonch menuliskan menurutnya gembala yang bertanggung jawab hendaknya memberi kebutuhan makanan, istirahat, ketenangan, berkembang biak, menikmati rumut hijau, merasakan bebas dari ancaman pemangsa dan pencuri. ${ }^{28}$ Domba adalah makhluk yang harus dilindungi oleh gembala. Dengan demikian teologi penggembalaan merupakan pemahaman yang mendalam dari rencana, cinta kasih Tuhan atas umat-Nya, dengan dasar penelusuran Alkitab dengan penerapannya yang maksimal kepada orang-orang yang digembalakan dalam satu sidang jemaat tertentu. Teologi penggembalaan adalah paduan antara pemahaman yang benar dari Alkitab serta tindakan yang berkesesuaian untuk memberi kenyamanan dan kesejahteraan. Kapic mmenuliskan teologi penggembalaan lebih dari sekadar kebajikan, kontemplasi

${ }^{26}$ Beth M. Stovell, "Yahweh as Shepherd-King in Ezekiel 34: A Linguistic-Literary Analysis of Metaphors of Shepherding," dalam Linguistic Biblical Studies, ed. oleh Stanley E. Porter, Gregory P. Fewster, dan Christopher D. Land (Brill, 2016), 200-230, https://doi.org/10.1163/9789004309364_008.

27 Gabriel Yobert Rajo, "Dosa Yerusalem dalam Yehezkiel 22:1-31: Kajian Biblika dan Implikasi Praktis," Jurnal IImu Teologi dan Pendidikan Agama Kristen 1, no. 2 (2020): 146, https://doi.org/10.25278/jitpk.v1i2.518.

${ }^{28}$ A Christian Jonch, Tuhankulah Gembalaku (Jakarta: Yayasan Komunikasi Bina Kasih, 2103). 
dan pengetahuan. ${ }^{29}$ Maka untuk memberikan penggembalaan yang sepenuhnya maka perlu memberikan kemampuan dan kapasitas diri sepenuhnya.

Tabel berikut merupakan ringkasan Yehezkiel 34 dalam hal tindakan Allah kepada gembala-gembala. Tindakan Allah ini didasari atas kinerja gembala yang secara sengaja lalai dan abai terhadap tugasnya.

\begin{tabular}{|c|c|}
\hline $\begin{array}{l}\text { Yang tidak diinginkan } \\
\text { Allah dari gembala }\end{array}$ & $\begin{array}{l}\text { Tindakan yang dilakukan } \\
\text { Allah kepada gembala }\end{array}$ \\
\hline $\begin{array}{ll}\text { tidak menggembalakan } & \text { domba-domba, } \\
\text { tetapi menyembelih (ay.3) } & \end{array}$ & $\begin{array}{l}\text { Aku sendiri akan menjadi } \\
\text { lawan gembala-gembala itu (ay.10.b) }\end{array}$ \\
\hline $\begin{array}{l}\text { tidak menguatkan yang lemah; tidak } \\
\text { mengobati yang sakit; tidak membalut yang } \\
\text { luka; tidak membawa yang tersesat; tidak } \\
\text { mencari yang hilang; menginjak-injak } \\
\text { domba dengan kekerasan dan kekejaman } \\
\text { (ay.4) }\end{array}$ & $\begin{array}{l}\text { Aku akan menuntut kembali domba- } \\
\text { domba-Ku dari mereka (ay.10.c) } \\
\text { akan memberhentikan mereka } \\
\text { menggembalakan domba-domba-Ku } \\
\text { (ay.10.d) }\end{array}$ \\
\hline $\begin{array}{l}\text { gembala-gembala-Ku tidak memperhatikan } \\
\text { domba-domba-Ku (ay. } 8 \mathrm{~b})\end{array}$ & \\
\hline $\begin{array}{l}\text { mereka itu menggembalakan dirinya sendiri } \\
\text { (ay.8c) }\end{array}$ & \\
\hline
\end{tabular}

Tabel. 2 Pembagian Yehezkiel 34 dari sisi isi

Dengan memperhatikan pola penulisan tabel di atas, maka Yehezkiel 34 adalah tulisan yang sepenuhnya nubuatan. Osborne menggambarkan peran yang kompleks seorang nabi dalam menyampaikan nubuat karena pesannya datang dari Allah untuk membangun hubungan yang rusak antara umat dengan Yahweh seturut hubungan kovenan yang telah ada diantara umat dan Allah itu sendiri. ${ }^{30}$ Brad E. Kelle menyatakan bahwa nubuatan adalah sebuah bentuk dari intermeditation antara Tuhan dan manusia (a form of intermediation between the divine and human). Serta sebagai sub-jenis dari praktik keagamaan yang lebih besar dari ramalan (non-teknis) sebagai fenomena sosio-historis yang dimiliki

29 Kelly M Kapic, Pedoman Ringkas Berteologi (Jakarta: Waskita Publishing, 2014).

30 Grant R. Osborne, Spiral Hermeneutika: Pengantar Komprehensif bagi Penafsiran Alkitab (Surabaya: Momentum, 2012), 308. 
oleh berbagai budaya kuno pada zamannya. ${ }^{31}$ Sihaloho menambahkan bahwa nubuat-nubuat dari nabi untuk hidup yang lebih sejahtera dalam hal kerohanian, sebab nabi dalam nubuatan itu mengungkapkan implikasi pemahaman atau pengertian mereka tentang Allah untuk masa depan. ${ }^{32}$ Berbagai aspek itu diterjemahkan oleh nabi dan ditulis dengan menggunakan bahasa yang mudah dipahami oleh manusia di zamannya. ${ }^{33}$ Menanggapi hal tersebut VanGemeren menuliskan bahwa nabi adalah warga Israel, dipanggil Allah, dan diberi kuasa oleh Roh. Nabi melayani sebagai jurubicara Allah, yang menerima wewenang dan penyataan dari Allah, yang menjadi gembala baik bagi umat Allah, yang mendemonstrasikan firman Allah dan misi dengan tanda-tanda. ${ }^{34}$ Dengan demikian nubuat merupakan bagian rencana Allah terhadap orang-orang pilihanNya secara khusus dan semua manusia secara lebih luas tentang isi hati-Nya terhadap kehidupan spiritualitas yang sebenarnya dalam relasi kepada Allah, yang disampaikan oleh nabi pada saat-saat genting, tenang atau dalam tekanan orang lain. Isi nubuat bisa tentang perihal yang telah lampau, atau pada saat nubuat diterima kemudian disampaikan hingga perihal yang akan terjadi di kemudian hari. Semua itu disampaikan untuk kehidupan yang lebih baik dari umat pilihanNya.

Menurut hemat peneliti, tindakan Allah pada ayat.10 yakni memberhentikan gembala-gembala merupakan satu tindakan nyata sebagai dampak ketidakmampuan dan kelalaian gembala. Kompetensi menjadi gembala

${ }_{31}$ Brad E. Kelle, "The Phenomenon of Israelite Prophecy in Contemporary Scholarship," SAGE Journals 12, no. 3 (2014): 275-23-, https://doi.org/10.1177/1476993X13480677.

32 Hery Sihaloho, "Nubuatan Tentang Mesias dalam Perjanjian Lama Berdasarkan Kitab Sejarah," Kurios 3, no. 1 (2018): 12-21, https://doi.org/10.30995/kur.v3i1.25.

33 Kosma Manurung, "Ketubim dan Nubuat," Pengarah: Jurnal Teologi Kristen 2, no. 2 (2020): 12940, https://doi.org/10.36270/pengarah.v2i2.24.

34 Willem A. VanGemeren, Interpreting the Prophetic Word: An Introduction to the Prophetic Literature of the Old Testament (Grand Rapids: Zondervan Academic, 1996), 32. 
adalah bagian perlengkapan yang diberikan Allah kepada orang yang dipanggil secara khusus dalam pelayanan penggembalaan. Paulus menuturkan ini kepada orang di Korintus dengan keyakinan bahwa atas perlengkapan dari Allah kepadanya dalam pelayanan (2Kor.4: 1-15).

Sebagai satu bagian dari teologi praktika, penggembalaan memasuki peran yang khusus dalam menghadapi tantangan hidup saat ini. Kecemasan, kekuatiran jemaat atas wabah tentu tidak bisa diabaikan, selain dampak yang dirasakannya seperti pengurangan gaji. Billy Graham menuliskan adanya jemaat yang kekurangan, kesulitan fisik, cemas dan kuatir, gembala jemaat perlu memberikan simpati yang mendalam dan memberikan bantuan nyata. ${ }^{35}$ Teologi praktika dapat diterapkan jika ada tindak lanjut (follow-up) yang nyata, jika jemaat yang mengalami permasalahan menemukan kelegaan atas tindakan gembala, maka ketenangan dirasakan. Inilah satu bentuk konkret dari tindakan memberi perhatian, yaitu menuntun jemaat (domba-domba) untuk menikmati ketenangan dan kenyamanan di dalam Tuhan.

Tantangan kehidupan jemaat dari masa ke masa memiliki perbedaan dan tingkat kesulitannya sendiri, namun Allah memberikan jalan agar manusia mampu untuk melewatinya (1Kor.13: 13). Seperti tindakan pembinaan dengan yang dilakukan Berton Silaban dalam usaha untuk memberikan pelayanan kepada pemuda pada masa pandemik. ${ }^{36}$ Kesulitan dan wujud pelayanan tatap muka yang hampir tidak dilakukan, dapat diatasi dengan pelaksanaan dengan media online,

35 Billy Graham, Pedoman Pelayanan Kristen (Jakarta: Scripture Union Indonesia, 2018).

${ }^{36}$ Bostang Berton Hamonangan Silaban Dan Hasahatan Hutahaean, "Model Pembinaan Remaja Di Era Pandemik Dengan Pa Bga," Jurnal PKM Setiadharma 1, no. 3 (2020): 53-58, https://doi.org/doi.org/10.47457/jps.v1i3.106. 
karena bebas dari jarak yang berjauhan. Gembala dapat melakukan pelayanan tanpa terikat oleh jangkauan waktu dan ruang. ${ }^{37}$

Gereja secara personifikasi memiliki tugas sebagai gembala. Karena itu tindakan penghakiman Allah juga ditujukan kepada gereja yang secara organisasi melupakan tugas penggembalaan. Herlince Rumahorbo menuliskan bahwa tugas gereja yang semakin kompleks, bersamaan dengan tugas pemberitaan pertobatan dan pemberian pengampunan dosa. ${ }^{38}$ Karena itu salah satu usulannya yang harus diperhatikan dan tetap dikerjakan adalah mengunjungi jemaat secara pribadi. Situasi yang sulit untuk bertatap muka tidak dapat menjadi alasan bagi gembala untuk melupakan tugas penggembalaan. Perkunjungan yang mulai bergeser dari pola tatap muka, telah mendapat jalan baru dengan media daring (online) dengan berbagai media dan aplikasi. Sianturi menuliskan istilah tersebut dengan teologi pastoral di ruang publik. ${ }^{39}$ Gembala hendaknya memiliki pola baru dalam penggembalaan dengan mengadakan percakapan sesuai dengan bidang kehidupan jemaat yang disertai dengan pembacaan firman Tuhan dan doa bersama. Sebab itu seorang Gembala diminta untuk berani maju di ruang publik dalam pendampingan-pendampingan kepada warga jemaat yang memerlukan perhatian, baik kepada warga jemaat atau masyarakat yang terabaikan (unreach people).

Gembala pada dasarnya melakukan tugas mengajar, berdoa, menegur dan menuntun dalam kesabaran, agar orang-orang yang berdosa menemukan pertobatannya kepada Allah. Karena itu dalam perannya sebagai pengajar, maka

\footnotetext{
37 Waharman, "Prinsip Penggembalaan Dalam Mazmur 23."

38 herlince Rumahorbo, "Keteladanan Yesus Sebagai Gembala Menjadi Dasar Pelayanan Hamba Tuhan Masa Kini," Phronesis: Jurnal teologi dan Misi 2, no. 2 (2020): 130-46, https://doi.org/10.47457/phr.v3i2.68.

39 Raymond Sianturi, "Teologi Pastoral di Ruang Publik," dalam Teologi-Teologi Kontemporer, ed. oleh Jan S Aritonang (Jakarta: Unit Publikasi dan Informasi STT Jakarta, 2018), 367-85.
} 
dapat dianalogikan/dipersamakan dengan guru atau pengajar lain, seorang gembala hendaknya mengajarkan firman Allah, menggembala penuh kasih dengan inovatif, kreatif dan memperhatikan prinsip edukatif. ${ }^{40}$ Yehezkiel 34: 4 menunjukkan tentang kekecewaan Allah terhadap gembala yang tidak menguatkan yang lemah, tidak mengobati yang sakit, tidak membalut yang luka, tidak membawa yang tersesat, tidak mencari yang hilang, menginjak-injak domba dengan kekerasan dan kekejaman. Mengajar dan menuntun dengan sabar adalah pekerjaan yang memerlukan totalitas dari para gembala. Hal ini diperlukan secara lebih nyata dalam keadaan yang semakin sulit dengan tantangan yang beragam di tiap zaman. Dalam dunia pengajaran dan perkembangan keilmuan, filsafat serta perkembangan teknologi menjadi kompetitor baru dalam teologi praktika, para jemaat telah memiliki banyak pilihan yang baru selain performa dan perangai Gembala secara nyata. Sandi menuliskan penelitiannya tentang model teacherpastor dari Yehezkiel 34 menyatakan bahwa guru juga harus mengambil peran sebagai gembala/pastor terhadap peserta didik. Gembala yang baik jika mampu mengangkat semangat orang-orang yang lemah dalam iman, menumbuhkan kepercayaan diri bagi yang minder serta setia dalam menjalankan tugasnya meski menghadapi situasi yang tidak mendukung. ${ }^{41}$ Peran inilah yang telah diterapkan oleh Yesus Kristus sebagai Gembala Sejati.

Kesungguhan juga menjadi hal penting dalam penggembalaan, menanggapi hal tersebut Hutahaean menyatakan bahwa orang-orang yang

\footnotetext{
40 Bongsu Parhusip, Hasahatan Hutahaean, dan Elda Theresia, "Penerapan Model Think-Pair and Share dalam Meningkatkan Hasil Belajar PAK pada Siswa SMP," Didache Jurnal Teologi dan Pendidikan Kristen 1, no. 2 (2020): 117-40, https://doi.org/10.46445/djce.v1i2.349.

${ }^{41}$ Sandy Ariawan, Kreativitas Mengajar Dan Implementasi Konsep Pastor-Teacher Dalam Kitab Yehezkiel Pasal 34 Dengan Tingkat Keberhasilan Pendidikan Agama Kristen (Kecamatan Tamalanrea: Cv. Mitra IImu, 2020).
} 
melayani dalam penggembalaan hendaknya menggembalakan domba yang diberikan Allah dengan sungguh-sungguh dan tidak mengacaukan. ${ }^{42}$ Susanta juga menanggapi hal tersebut namun dalam sudut pandang koinonia, yakni agar gereja membangun komunitas orang Kristen beriman yang bertumbuh dalam iman. ${ }^{43}$ Keutamaan melayani bagi Allah untuk pertumbuhan iman jemaat, agar berdampak dalam keberhasilannya menghadapi tantangan zaman yang kian beragam. Sebab spiritualitas yang sehat dan benar, bagi Hanock merupakan jalan bagi jemaat untuk mengenal dirinya dengan benar. ${ }^{44}$ Pengenalan Allah yang benar akan lebih mudah untuk untuk mengenal diri sendiri dan kekuatan dalam menghadapi tantangan zaman. Hal ini dapat terwujud melalui pola penggembalaan yang mengikuti pola perkembangan tantangannya. Perwujudan kasih Allah kepada manusia berdosa oleh Simanjuntak disebut juga sebagai "kemegahan, keluhuran dan keagungan" yang menjadi kekhasan Kristen oleh Kristus. ${ }^{45}$ Dalam penggembalaan, Allah menginginkan pengutamaan hasrat dan pikiran gembala bagi domba-domba-Nya. Gembala yang ingin memenuhi kebutuhan diri sendiri dari keuntungan menggembalakan tidak bisa menuntun dan membaringkan domba ke rumput yang hijau dan air tenang.

\section{KESIMPULAN}

Penelitian ini merupakan hasil studi dari Yehezkiel 34 yang berangkat dari situasi penggembalaan yang kian kompleks dari waktu ke waktu, terutama pasca

\footnotetext{
42 Hutahaean, Pelayan Tuhan di Gereja dan Masyarakat.

43 Yohanes Krismantyo Susanta, "Gereja Sebagai Persekutuan Persahabatan Yang Terbuka Menurut Jurgen Moltmann," Visio Dei: Jurnal Teologi Kristen 2, no. 1 (2020): 105-26, https://doi.org/10.35909/visiodei.v2i1.86.

44 Edward E. Hanock, "Potensi Diri dan Gambar-Rupa Allah," Didache Jurnal Teologi dan Pendidikan Kristen 1, no. 1 (2019): 24-34, https://doi.org/e-ISSN 2715-2758.

45 Linda Zenita Simanjuntak, "Hiasi Dirimu Dengan Kemegahan dan Keluhuran Refleksi Ayub 40:19," dalam Tetap Setia Di Jalan Tuhan : Kumpulan Tulisan Dalam Rangka Mensyukuri Ulang Tahun Pdt. Dr. Edison Djama, ed. oleh Stenly R Paparang (Surabaya: Bible Culture Study, 2020), 154-60.
} 
pandemik Februari 2020 lalu. Bukan saja di Indonesia namun di seluruh belahan dunia. Gembala-gembala telah tiba saatnya untuk bergerak melampaui zaman dan berbagai tantangan yang berbeda di tiap zaman. Sebab seiring bergantinya zaman, tantangan yang ada juga berbeda. Gembala dituntut untuk memberikan segala kapasitas yang dimiliki untuk menuntun jemaat dalam menjalani kehidupan yang memberi tantangan-tantangan berbeda di tiap era. Allah dengan kasih (chesed, hesed atau kasih setia, cinta kasih, kasih sayang Allah) yang tidak terhingga kepada umat pilihanNya mempunyai hasrat (passion) untuk memberikan ketenganan, kenyamanan kepada domba-dombaNya hingga ada kesadaran bahwa Allah adalah Gembala Sejati bagi mereka. Teologi pengembalaan dari Yehezkiel 34 menekankan kembali penggembalaan yang tulus, setia pada perintah Alah dan tidak abai terhadap domba-domba yang diberikan Allah padanya, bagaimanapun situasi yang dihadapi. Teologi praktika akan tetap mendapat tantangan-tantangan baru di setiap zaman, namun Alkitab terus memberi pegangan bagi Gembala untuk memberi ketenangan dan kenyamanan bagi domba-domba.

\section{DAFTAR PUSTAKA}

Ariawan, Sandy. Kreativitas Mengajar Dan Implementasi Konsep Pastor-Teacher Dalam Kitab Yehezkiel Pasal 34 Dengan Tingkat Keberhasilan Pendidikan Agama Kristen. Kecamatan Tamalanrea: Cv. Mitra Ilmu, 2020.

Balchin, John, Peter Cotterell, Mary Evans, Gilbert Kirby, Peggy Knight, dan Derek Tidball. Intisari Alkitab Perjanjian Lama. Jakarta: Scripture Union Indonesia, 2016.

Drane, John. Memahami Perjanjian Lama; Dari Bapa Leluhur sampai Kerajaan Bersatu. Jakarta: Scripture Union Indonesia, 2017.

Memahami Perjanjian Lama II: dari Kerrajaan Terpecah Sampai Pascapembuangan. Jakarta: Scripture Union Indonesia, 2017. 
Fowler, JW. "Teologi Praktika dan Pembentukan Hidup Orang Kristen.” Dalam TEologi dan Praksis Pastoral Antologi Teologi Pastoral, disunting oleh Tjaard G Hommes dan E Gerrit Singgih, 355-78. Yogyakarta: Kanisius, 1992.

Graham, Billy. Pedoman Pelayanan Kristen. Jakarta: Scripture Union Indonesia, 2018.

Green, Joel B. Memahami Nubuatan. Disunting oleh James Pantou. Jakarta: Persekutuan Pembaca Alkitab, 2005.

Hamzah, Amir. Metode Penelitian Kepustakaan. Revisi. Malang: Literasi Nusantara, 2020.

Hanock, Edward E. "Potensi Diri dan Gambar-Rupa Allah." Didache Jurnal Teologi dan Pendidikan Kristen 1, no. 1 (2019): 24-34. https://doi.org/eISSN 2715-2758.

Hutahaean, Hasahatan. Pelayan Tuhan di Gereja dan Masyarakat. Luwuk: Pustaka Star's Lub, 2020.

Hutahaean, Hasahatan, Bonnarty Steven Silalahi, dan Linda Zenita Simanjuntak. "Spiritualitas Pandemik: Tinjauan Fenomenologi Ibadah Di Rumah." Evangelikal: Jurnal Teologi Injili dan Pembinaan Warga Jemaat 4, no. 2 (1 Agustus 2020): 234-49. https://doi.org/10.46445/ejti.v4i2.270.

Johannis, Abraham. "Peran Gembala Dalam Upaya Pencegahan Penyalahgunaan Narkoba Pada Anak Remaja.” Dalam Moderasi Teologi Kristen, 248-67. Jakarta: Covindo, 2020.

Jonch, A Christian. Tuhankulah Gembalaku. Jakarta: Yayasan Komunikasi Bina Kasih, 2103.

Kapic, Kelly M. Pedoman Ringkas Berteologi. Jakarta: Waskita Publishing, 2014.

Kartika, Casthelia. "Meninjau Ulang Metode Teologi Praktika Dalam Karya Ilmiah Di Bidang Pendidikan Teologi." Jurnal Amanat Agung 9, no. 1 (2013): 101-18. https://doi.org/10.47754/jaa.v9i1.124.

Kelle, Brad E. "The Phenomenon of Israelite Prophecy in Contemporary Scholarship." SAGE Journals 12, no. 3 (2014): 275-23-. https://doi.org/10.1177/1476993X13480677.

Lumbantobing, Darwin. "Pendeta Dalam Fungsi Koinonia, Marturia dan Diakonnia." Dalam Merangkai Teologi Kehidupan Terkini, disunting oleh Wilda Simanjuntak, 1-18. Siantar: L-SAPA, 2008.

Manurung, Kosma. "Ketubim dan Nubuat." Pengarah: Jurnal Teologi Kristen 2, no. 2 (2020): 129-40. https://doi.org/10.36270/pengarah.v2i2.24. 
Osborne, Grant R. Spiral Hermeneutika: Pengantar Komprehensif bagi Penafsiran Alkitab. Surabaya: Momentum, 2012.

Parhusip, Bongsu, Hasahatan Hutahaean, dan Elda Theresia. "Penerapan Model Think-Pair and Share dalam Meningkatkan Hasil Belajar PAK pada Siswa SMP.” Didache Jurnal Teologi dan Pendidikan Kristen 1, no. 2 (2020): 117-40. https://doi.org/10.46445/djce.v1i2.349.

Pattinama, Yenny Anita. "Pastoral Konseling Menurut Yehezkiel 34:16 Sebagai Upaya Pemulihan Mental." SCRIPTA: Jurnal Teologi dan Pelayanan $\begin{array}{lllll}\text { Kontekstual } & 6, & \text { no. } & 2 & \text { (2018): }\end{array}$ https://doi.org/10.47154/scripta.v6i2.53.

Purba, Asmat. "Tanggung Jawab Orang tua Kristen dalam Mendidikan Anak Menyikapi Pandemi Covid-19." EPIGRAPHE: Jurnal Teologi dan $\begin{array}{llllll}\text { Pelayanan Kristiani } & 4 \text {, no. } & 1 & \text { (2020): }\end{array}$ https://doi.org/10.33991/epigraphe.v4i1.148.

Rajo, Gabriel Yobert. "Dosa Yerusalem dalam Yehezkiel 22:1-31: Kajian Biblika dan Implikasi Praktis." Jurnal Ilmu Teologi dan Pendidikan Agama Kristen 1, no. 2 (2020): 144-62. https://doi.org/10.25278/jitpk.v1i2.518.

Riemer, G. Jemaat Yang Pastoral; Kunjungan Rumah Pacu Jantung Pertumbuhan Gereja. Jakarta: Yayasan Komunikasi Bina Kasih, 2005.

Rumahorbo, Herlince. "Keteladanan Yesus Sebagai Gembala Menjadi Dasar Pelayanan Hamba Tuhan Masa Kini." Phronesis: Jurnal teologi dan Misi 2, no. 2 (2020): 130-46. https://doi.org/10.47457/phr.v3i2.68.

Saly, Jansakti Saddu, Dan Hasahatan Hutahaean. "Pengaruh Khotbah Dalam Ibadah Minggu Terhadap Kedewasaan Iman Jemaat Di Gksi Merauke." Visio Dei: Jurnal Teologi Kristen 2, no. 2 (2020): 225-43. https://doi.org/10.35909/visiodei.v2i2.165.

Siahaan, Simon Petrus. "Konsep Gembala Menurut Yehezkiel 34:1-16 Serta Implikasinya Bagi Gembala Jemaat.” Missio Ecclesiae 4, no. 2 (2015): 123-54. https://doi.org/ISSN: 2721-8198.

Sianturi, Raymond. "Teologi Pastoral di Ruang Publik." Dalam Teologi-Teologi Kontemporer, disunting oleh Jan S Aritonang, 367-85. Jakarta: Unit Publikasi dan Informasi STT Jakarta, 2018.

Sihaloho, Hery. "Nubuatan Tentang Mesias dalam Perjanjian Lama Berdasarkan Kitab Sejarah." Kurios 3, no. 1 (2018): 12-21. https://doi.org/10.30995/kur.v3i1.25.

Silaban, Berton Bostang Hamonangan. "Strategi Konseling Yesus Menurut Lukas 24:13-25 Dan Kontribusinya Terhadap Konseling Krisis Masa Kini." Asteros 3, no. 2 (2016): 39-50. https://doi.org/ISSN. 2356-2587. 
Silaban, Bostang Berton Hamonangan, Dan Hasahatan Hutahaean. "Model Pembinaan Remaja Di Era Pandemik Dengan Pa Bga." Jurnal PKM $\begin{array}{lllll}\text { Setiadharma } & 1, & \text { no. } & 3 & \text { (2020): }\end{array}$ https://doi.org/doi.org/10.47457/jps.v1i3.106.

Simanjuntak, Linda Zenita. "Hiasi Dirimu Dengan Kemegahan dan Keluhuran Refleksi Ayub 40:1-9." Dalam Tetap Setia Di Jalan Tuhan: Kumpulan Tulisan Dalam Rangka Mensyukuri Ulang Tahun Pdt. Dr. Edison Djama, disunting oleh Stenly R Paparang, 154-60. Surabaya: Bible Culture Study, 2020 .

Simon, Simon, Dan Lindin Anderson. "Covid-19 Memudarkan Rasa Kemanusiaan Terhadap Sesama Dan Implikasinya Bagi Orang Percaya.” Sabda: Jurnal Teologi Kristen 1, no. 2 (2020): 85-104. https://doi.org/ISSN: 2722-306X.

Stovell, Beth M. "Yahweh as Shepherd-King in Ezekiel 34: A Linguistic-Literary Analysis of Metaphors of Shepherding." Dalam Linguistic Biblical Studies, disunting oleh Stanley E. Porter, Gregory P. Fewster, dan Christopher D. Land, 200-230. Brill, 2016. https://doi.org/10.1163/9789004309364_008.

Sumiwi, Asih Rachmani Endang. "Gembala Sidang yang Baik Menurut Yohanes 10 : 1-18." HARVESTER: Jurnal Teologi dan Kepemimpinan Kristen 4, no. 2 (2019): 74-93. https://doi.org/e-ISSN 2685-0834.

Susanta, Yohanes Krismantyo. "Gereja Sebagai Persekutuan Persahabatan Yang Terbuka Menurut Jurgen Moltmann.” VISIO DEI: JURNAL TEOLOGI $\begin{array}{lllll}\text { KRISTEN } & 2, & \text { no. } & 1 & \text { (2020): }\end{array}$ https://doi.org/10.35909/visiodei.v2i1.86.

Telaumbanua, Arozatulo. "Peran Gembala Sidang Sebagai Pendidik Dalam Pertumbuhan Rohani Jemaat." FIDEI: Jurnal Teologi Sistematika dan Praktika 2, no. 2 (2019): 362-87. https://doi.org/10.34081/fidei.v2i2.45.

Teng, Michael, dan Margaret Carmia. "Sketsa Pelayanan Gereja Sebelum, Selama, Dan Sesudah Masa Pandemi Covid-19." Veritas : Jurnal Teologi dan Pelayanan 19, no. 2 (2020): 201-13. https://doi.org/10.36421/veritas.v19i2.432.

VanGemeren, Willem A. Interpreting the Prophetic Word: An Introduction to the Prophetic Literature of the Old Testament. Grand Rapids: Zondervan Academic, 1996.

Waharman, Waharman. "Prinsip Penggembalaan Dalam Mazmur 23." Manna $\begin{array}{lllll}\text { Rafflesia } & 1, & \text { no. } & 2 & \text { (2015): }\end{array}$ https://doi.org/10.38091/man_raf.v1i2.47. 